\title{
Performance evaluation of water supply services in Chitungwiza: How water supply services mirrors poor governance and lack of management
}

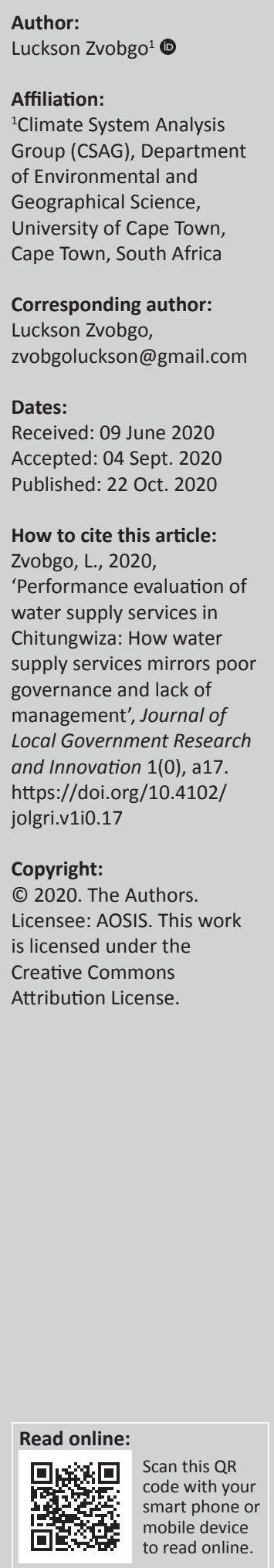

Background: Provision of reliable water services is crucial for urban livelihood. In Chitungwiza, provision of water services has been deteriorating since the millennium with residents losing hope for better services. The poor supply of municipal water in Chitungwiza has led to a chronic 'dry taps situation' where household taps are dry from periods of several consecutive days to months.

Aim: This article assesses the water supply challenges in Chitungwiza through performance evaluation of the water supply services.

Setting: The study was conducted in 26 suburbs in the four residential zones of Chitungwiza Municipality.

Methods: Performance evaluation of water supply services was carried out using seven performance indicators: coverage of water supply connection, extent of metering of water connections, presence of leakages, extent of non-revenue water, continuity of water supply, quality of water supplied and efficiency in redressal of customer complaints. Two hundred and ninetyeight semi-structured questionnaires were administered in four residential zones of Chitungwiza. Water distribution system surveillance and key informant interviews were also conducted.

Results: The results indicate high non-revenue water, poor water infrastructure maintenance, lack of water investment leading to widespread leakages in the distribution system, poor water quality supply and unreliable services provision. A majority, $80.2 \%$, rated the municipal water supply services as poor. To cope with this new reality, households in Chitungwiza implemented a 'source switch' to new sources.

Conclusion: Household shallow wells were identified as the main adapting strategy with $51.7 \%$ households relying on wells despite concerns about the water quality of the wells. Chitungwiza municipality should implement structural reforms that allow the current water service provision to improve.

Keywords: performance evaluation; dry taps; water services provision; water infrastructure; Chitungwiza.

\section{Introduction}

Provision of reliable water services is key for sustainable development of cities (Yadav et al. 2014), human health and ecosystem management (Aboelnga et al. 2020). In Africa and other developing regions, however, urban water supply is facing numerous challenges including institutional bottlenecks (Ainuson 2010; Britto, Maiello \& Quintslr 2019; Larsen et al. 2016), old and weak water infrastructure (Padowski, Carrera \& Jawitz 2016; Rouse 2014) that lacks investment (Zimmerman, Mihelcic \& Smith 2008), poor governance and weak institutions (Adams \& Zulu 2015). Chitungwiza is a classic case study of a city in a developing region facing multi-governance and institutional challenges that for the past 15 years have led to residents having dry taps that last for consecutive days or even months. With growing concerns about the impacts of climate change and population growth on urban water supply in developing countries (Aboelnga et al. 2020; Bischoff-Mattson et al. 2020; Chen et al. 2015; Roberts 2008), cities need to develop strategic plans to ensure sustainable development of water supply systems and resilient services. However, the situation in Chitungwiza is contrary to this; the city is off track in achieving sustainable cities development as far as provision of reliable water services is concerned.

Chitungwiza is the third largest and the fastest-growing urban centre in Zimbabwe with a population of 386000 people. The town was established in 1978 as a dormitory suburb of the 
capital city, Harare. Chitungwiza gained full municipal status in 1981 (Japanese International Cooperation Agency 2013). Chitungwiza municipality has, since the millennium, been failing to provide basic services, such as reliable water access and regular waste collection and removal (Africa Water Facility 2009). The water crisis in Chitungwiza reflects the direction the country has been pulling towards for the past three decades in terms of management and development. The water situation in Chitungwiza for the past two decades reflects a retrogressive development process in Zimbabwe revealed through deterioration of basic services and livelihoods across the country. Despite the chronic poor water services provision in Chitungwiza, no study has ever been conducted to explore the water supply situation and how it could be improved.

On an average, cities and towns in Africa are growing at 5\% per annum (World Bank 2014). As a result, municipalities are facing considerable challenges to meet the growing demand (Adams 2017; Clifford Holmes et al. 2014) and Chitungwiza is one such example. The recent rapid urbanisation and population growth has resulted in water supply services in Chitungwiza failing to keep up the pace. The situation in Chitungwiza has been intensified by a dilapidated water supply infrastructure that for the past three decades has lacked investment. The involvement of the central government through the Ministry of Local Government and retrogressive policies has also contributed to the water services failure in Chitungwiza (Nyikadzino \& Nhema 2015). Chitungwiza's water system needs immediate investments, but it will be necessary to investigate both the system failure and governance issues to ensure that the right approach to address the problems is used. This research provides a broad understanding of the current water supply and service provision in Chitungwiza and how this is preventing the city from achieving its sustainable cities development agenda.

Because of lack of consistency in water supply in Chitungwiza, most customers have lost confidence and trust in the water service provision. This has affected the patterns of paying for water, leading to Chitungwiza municipality failing to mobilise the financial resources needed for meaningful water development projects and upgrade of the system to keep water supply continuous. This is because the municipal water system operations are largely financed bywater bills paid by consumers. Most residents have sunk shallow home wells as an alternative source to unreliable municipal water supply in Chitungwiza. However, there are risks of these wells drying up and of water quality issues, jeopardising human health, hence a consistent potable municipal water supply is indispensable.

For the past decade and half, Chitungwiza has been implementing a strict water rationing programme, where each zone gets water access for at least 24-48 h per week. More than $40 \%$ of the residential suburbs in Chitungwiza experience deficiencies in supply that can last from $24 \mathrm{~h}$ to several days (Africa Water Facility 2009). Failure of the economy of Zimbabwe during the past two decades, along with the loss of donor funds has resulted in virtually no investment in water service delivery in Zimbabwe. The water supply has run down in Chitungwiza and the repairs and maintenance of services have completely disappeared (Hove \& Tirimboi 2011). Households are left with no option but to resort to unprotected wells as a coping mechanism to the on-going water supply problems. The study was conducted to give answers to three fundamental questions for Chitungwiza municipality in its quest to address the chronic water supply challenges to achieve sustainable cities development objectives:

- What are the water supply service challenges in Chitungwiza?

- Do the current water supply services in Chitungwiza meet both local and international benchmark standards of good practice?

- What are the residents' opinions regarding water supply services provision in Chitungwiza and how do these opinions shape household coping mechanisms?

\section{Why are reliable urban water services pertinent in sustainable cities development?}

With growing water demand because of competing water users in urban water supply in developing regions under the uncertainties of climate change, reliable water supply services that limit water losses and prioritise good urban water management and governance are fundamental. This underscores the need to have reliable urban water supply services that are sustainably managed and governed. This article is premised on the relevance of reliable urban water supply in the attainment of sustainable cities development agenda. The availability and supply of sufficient drinking water of acceptable quality is becoming a fundamental global challenge (Ahmadi et al. 2020; Bischoff-Mattson et al. 2020). In Chitungwiza, provision of reliable water supply and service is facing many challenges because of poor governance, unattended water system and lack of good management. These two will potentially reverse the gains and achievement of sustainable cities development agenda in Chitungwiza.

The recent development of urban water supply shortages and interrupted services across the globe has led to the discoveries of new terms such as 'day zero' (Bischoff-Mattson et al. 2020; Booysen, Visser \& Burger 2018). In most cases, day zero scenarios are associated with climatological deficit (Ahmadi et al. 2020; Booysen et al. 2018). Day zero scenario threatens the future of sustainable cities development as cities would struggle to provide reliable water supply services (Ahmadi et al. 2020). However, in Chitungwiza, the fears of day zero would be more likely to emerge from the lack of municipal capacity to deliver sustainable, reliable water services than the interruption of services caused by severe climatic conditions and droughts. Thus, it is critical that checks and balances are applied in Chitungwiza to assess water service delivery and identify areas that need immediate attention for sustainable water services development. 
Addressing water supply governance challenges in Chitungwiza resonates with the global agenda of improving access to safely managed water systems that promotes sustainable development. Current water supply and management in Chitungwiza is not aligning with the future sustainable cities' development. This article, therefore, focuses on assessing the key water supply indicators that are vital for Chitungwiza to meet reliable water supply services in attaining the sustainable cities development goals.

\section{Water infrastructure and supply services in Chitungwiza}

Water in Chitungwiza is public and solely supplied by Chitungwiza municipality through two sources: potable water distribution system and municipal boreholes. The potable water is supported by 79 municipal boreholes. Chitungwiza municipality does not have its own potable water treatment plant but buys potable water from Harare City. Therefore, for Chitungwiza to sustainably keep its supply, residents should pay for water services so that the municipality is able to buy water from City of Harare.

TABLE 1: Details of water property connections according to four zones of Chitungwiza as of 2016

\begin{tabular}{lcccccccc}
\hline Zone & HDC & MDC & LDC & CC & IC & InC & Others & Total \\
\hline Seke North & 14121 & 418 & 384 & 597 & 0 & 52 & 0 & 15572 \\
Seke South & 13220 & - & - & 346 & 0 & 54 & 0 & 13620 \\
Zengeza & 14355 & 1042 & - & 348 & 323 & 97 & 0 & 16165 \\
St Mary's & 9219 & - & 352 & 289 & 0 & 55 & 152 & 10067 \\
\hline Total & $\mathbf{5 0 ~ 9 1 5}$ & $\mathbf{1 4 6 0}$ & $\mathbf{7 3 6}$ & $\mathbf{1 5 8 0}$ & $\mathbf{3 2 3}$ & $\mathbf{2 5 8}$ & $\mathbf{1 5 2}$ & $\mathbf{5 5 4 2 4}$ \\
\hline
\end{tabular}

Source: Service Level Benchmarking (SLB), 2016, Chitungwiza municipality SLB report, Final Report, Service Level Benchmarking, Chitungwiza

$\mathrm{CC}$, commercial connections; HDC, high density connection; IC, industrial connection; InC, institutional connections; MDC, medium density connections; LDC, low density suburbs.
Residential potable water in Chitungwiza is distributed and managed based on the four zones (Table 1). Harare is currently supplying a volume of 25 megalitres (ML) per day. The current supply volume from Harare was reduced because Chitungwiza municipality is in debt to Harare Water. The supply volume is based on the purchasing power of Chitungwiza municipality. The current supply is only able to provide one-third of the total water required in Chitungwiza. This has resulted in serious water supply rationing in the city.

A main water distribution pipeline that supplies water to Chitungwiza comes from the Prince Edward Water Treatment Plant. It leaves the treatment plant at an elevation of $1467 \mathrm{~m}$ to Chitungwiza. With this elevation, lower altitude areas of Chitungwiza (Figure 1), Zengeza and St Mary's zones are fed directly using gravitational force. This main distribution pipeline is $600 \mathrm{~mm}$ in diameter and it splits into two mains of $525 \mathrm{~mm}$ and $450 \mathrm{~mm}$ to the night storage reservoir (NSR) in the Seke north zone (Figure 1). The NSR supplies the two Seke zones (Seke north and south) because they are located on higher ground that requires pumping from the NSR to boost water pressure. The initial NSR design storage capacity was 46 ML for 3 days (World Bank Report 2014). As a result of population growth and city expansion, the NSR is now unable to supply water for at least 2 days to these two zones. This current setting has caused irregularities of supply across the four zones. The two zones that are supplied through gravitational force usually have good pressure and the other two which require pumping experience low pressure. This is because of consistent black out caused by load shedding affecting Zimbabwe. The Seke zones have been severely impacted, so that even during the scheduled time when they

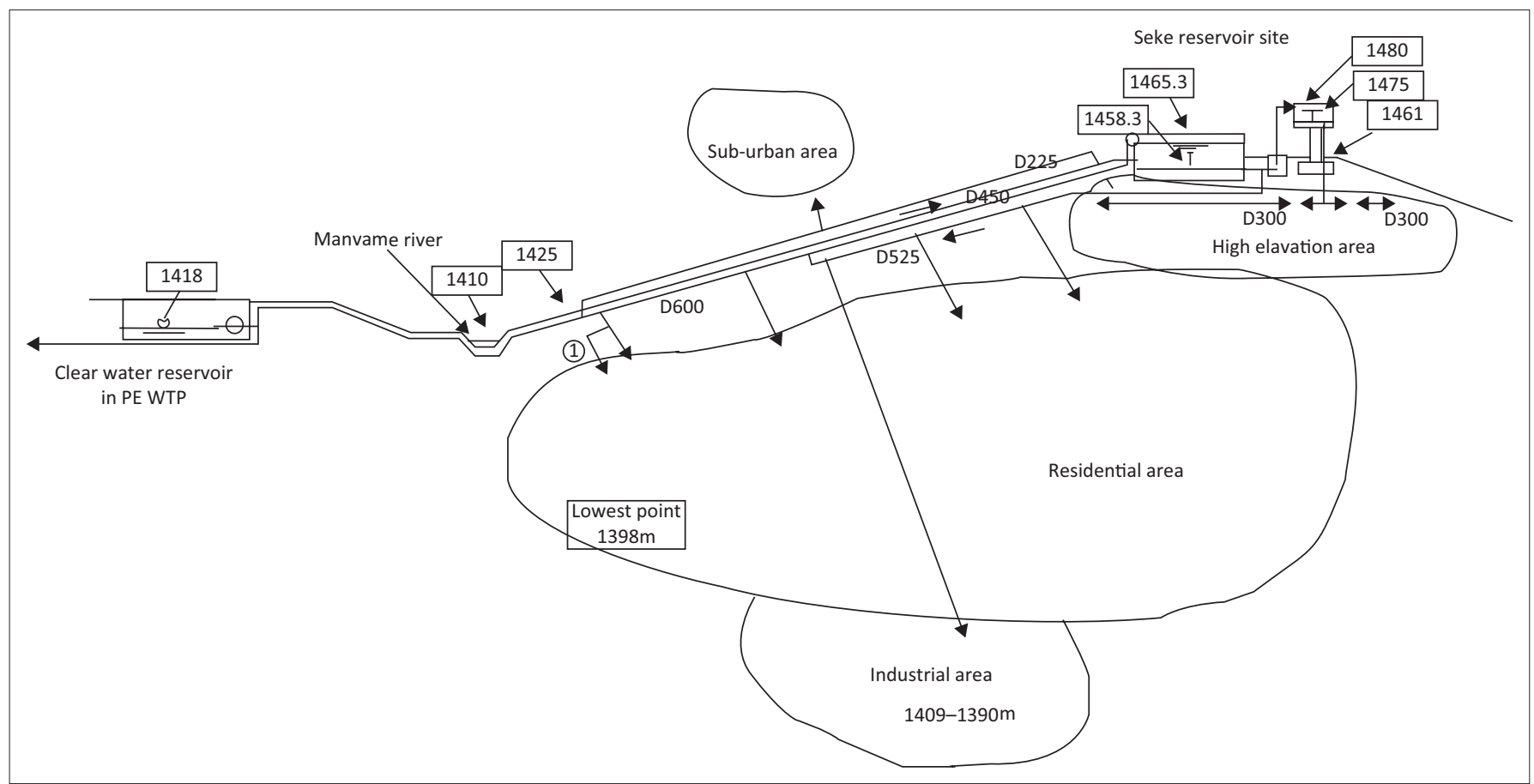

Source: Japanese International Cooperation Agency (JICA) Report of 2013. A project for the improvement of water supply, sewage and solid waste management in Chitungwiza in the Republic of Zimbabwe

PE WTP, Prince Edward Water Treatment Plant.

FIGURE 1: Current water supply distribution system for Chitungwiza. 
should receive water, if there is load shedding it means no water for them. The problem is exacerbated by lack of meaningful infrastructure development of the water system for the past three decades.

The current water supply rationing in Chitungwiza applies to the residential connections only (World Bank Report 2014). This has led to cases of water vending amongst households with no alternative water sources, that is, wells and boreholes (Gambe 2019). The use of shallow household wells as the main coping mechanism for the unreliable municipal water supply services present challenges such as the drying up of these wells during the dry season around October and November (Gambe 2019). There are also issues of water quality associated with the use of wells and other new sources. Planning for an efficient and reliable water delivery system by the municipality is therefore fundamental for human health, better livelihoods, achievement of Sustainable Development Goal 6 (SDG 6) and economic development in Chitungwiza. There is an urgent need for water system development to address the dry tap situation, moving to a more reliable and sustainable supply in order to meet current and future demand as the city's population keeps growing exponentially.

\section{Methods}

Performance evaluation of the water supply services in Chitungwiza was carried out using the assessment of compliance with the seven performance indicators: coverage of water supply connection, extent of metering of water connections, presence of leakages, extent of nonrevenue water (NRW), continuity of water supply, quality of water supplied and efficiency in redressing customer complaints. To assess the above performance indicators, the study used both qualitative and quantitative research approaches. The reason for mixing qualitative and quantitative research approaches was to allow appropriate assessment of all the seven indicators. This is because indicators such as the perceptions of the quality of water supplied by municipality and efficiency of redressing customer complaints are best assessed using a qualitative research approach. Data collection and field observations involved a three key strategic approach in the systematic order given here:

- Surveillance of the water supply system to assess the condition of the infrastructure.

- Conduct key informant interviews with the Chitungwiza municipality water department.

- Household data collection across the four residential zones of Chitungwiza.

\section{System surveillance}

The main aim of surveilling the water supply and distribution system and the related infrastructure was to determine the exact areas in the system that need immediate attention because an unmaintained system produces leaks and bursts, increasing NRW. This poses management challenges that lead to interruption of water supply services. Non-revenue water for Chitungwiza was calculated using the method proposed by Yadav et al. (2014) as presented in Equation 1:

Total water produced and put into

$\mathrm{NRW}=\frac{\text { the transmission and distribution system }}{\text { Total water sold }} \times 100$

Data on water sold to consumers for the year under study was obtained from Chitungwiza municipality finance department. Data on water purchased from Harare water and put into the residential transmission and distribution system were obtained from Chitungwiza municipality water department through district bulk water meter readings located in the four residential zones.

\section{Key informant interviews}

Key informant interviews were conducted in May 2017. The main reason for conducting key informant interviews was to understand the technical challenges that are facing Chitungwiza water department in terms of budgets, procurement, finance and engineering capacities. Three key interviews were held with the Director of Water Department, the Chief Technician of the faults section and the Director of Revenue Collection and Finance.

\section{Household questionnaires and interviews}

Household semi-structured questionnaire surveys were conducted to solicit information on the following six performance indicators: coverage of water supply connection, water supply system maintenance and service, presence of leakages, continuity of water supply, quality of water supplied, efficiency in redressal of customer complaints. The questions sought to understand the extent of the problems and to gain the deeper thoughts and perspectives of the households towards the municipal water services provision. A purposive sampling technique was used to administer a total of 298 semi-structured questionnaires between May and July 2017 (see Table 2) across the four residential zones of Chitungwiza. Thus, households were selected at random at the interviewer's discretion. However, issues such as presence of leakages in the surrounding areas were also considered in selecting households within suburbs. Randomisation was used to avoid bias.

TABLE 2: Sample size and distribution across the study area.

\begin{tabular}{lccc}
\hline Zone & Questionnaires & Water connections & Sample size (\%) \\
\hline Seke North & 77 & 14539 & 0.5 \\
Seke South & 49 & 13220 & 0.4 \\
Zengeza & 103 & 15397 & 0.7 \\
St Mary's & 69 & 9213 & 0.7 \\
\hline Total & $\mathbf{2 9 8}$ & $\mathbf{5 2 3 6 9}$ & $\mathbf{0 . 6 \dagger}$ \\
\hline$n=298$. & & & \\
$\dagger$, Average sample. & & &
\end{tabular}


The questionnaire had three main sections: the first part focused on the major problems with the current water supply services in Chitungwiza based on the performance indicators that were measured. The aim was to unpack all the water supply challenges faced by households. The second section focused on whether households were satisfied with the water services they are receiving and their perception towards the services. The last section focused on the measures or coping strategies implemented by households to address dry taps situation in Chitungwiza and the other problems in the service provision.

\section{Definition and measurement of the performance indicators used in this study}

Box 1 describes the performance indicators and the benchmark used to assess and measure system performance for the six performance indicators. Both local and international benchmark targets were considered varying with the indicator being assessed.

\section{Ethical consideration}

Ethical clearance was not required for the study. CUREC Reference Number: SSD/CUREC1A/BSG_C1A-17-02.

\section{Results and discussion}

Table 3 shows a summary of the socio-economic attributes of the households/respondents and the key water supply issues investigated in Chitungwiza.

\section{Performance evaluation}

Chitungwiza municipality is failing to meet the benchmark of the six indicators (Box 1) used that are key for water services delivery. Table 4 shows a summary of the performance indicators used to evaluate Chitungwiza's water supply system and service provision. A detailed description of the indicators is given in the subsequent 'Results and Discussion' sections.

\section{Status of Chitungwiza water supply}

The water supply in Chitungwiza was observed to be highly variable across the 26 major suburbs, ranging from $20 \mathrm{~min}$ to 3 days in a week. A full-scale survey was conducted on the municipal water distribution system to identify possible sources of NRW through system leakages, illegal connections and issues of water theft. The condition of the municipal boreholes and other water-related infrastructure were also assessed.

\section{Non-revenue water}

The calculated NRW was 55\%, which is much higher than expected for urban water utilities. However, the calculations

TABLE 3: Descriptive socio-economic data and summary results of key water supply issues.

\begin{tabular}{lcc}
\hline Characteristics of household head & Number & Proportion (\%) \\
\hline Gender & 58 & 55 \\
Female & 134 & 45 \\
Male & & \\
Age & 224 & 75.2 \\
$21-54$ & 60 & 20.1 \\
$>55$ & & \\
Education & 189 & 63.4 \\
Ordinary level & 26 & 8.7 \\
Advance level & 67 & 22.5 \\
Degree/tertiary & & \\
Water quality & 28 & 9.4 \\
Good & 269 & 90.3 \\
Poor & 122 & 40.9 \\
Experience leakages between 2016 and 2017 & & \\
Water metering issues & 19 & 3.4 \\
Stolen meter & 32 & 10.9 \\
Malfunctioning meter & & \\
Household alternative water sources & 154 & 51.7 \\
Well & 39 & 13.1 \\
Private boreholes with bulk tanks & & \\
Issues with pressure of municipal water supply & 36.7 \\
Very low-pressure cases & & 5.4 \\
Coverage of water supply connections & & \\
Suburbs with water connections & & \\
Suburbs without connections & & \\
\hline & & \\
\hline
\end{tabular}

BOX 1: Description of performance indicators used to assess Chitungwiza Municipality water supply services.

Coverage of water supply connection - this measured the total number of suburbs in the Chitungwiza residential service area that are formally connected to the municipal water supply network with direct service connections considered as a benchmark to know the coverage of water supply connection. This benchmark was based on the UN Sustainable Development Goals (water for all). It was measured in percentage (\%). The benchmark was set at $100 \%$. The study did not use individual household connections because the study was based on a sample; it would have been ideal to use household connections as they are more accurate, only if the whole population was considered.

Extent of metering of water connections and presence of leakages: This was a ratio of fully working household meters to that of stolen and non-functional meters. Water is a basic need, and the supply of potable water to residents at their doorstep involves significant costs in building, operating and maintaining a system to do so. In a water supply system, the quantum of service provided to citizens is directly measurable, and therefore it is necessary that all the water supplied to all categories of consumers should be metered. Metering also induced efficiency in use of water, identification of physical leakages and administrative black holes in the system. It was measured in percentage (\%).

Extent of non-revenue water: Non-revenue water (NRW) measured the extent of water bought by Chitungwiza municipality that does not earn the municipality any revenue. This was computed as the difference between the total water bought and transmitted to residential zones and the total water sold expressed as a percentage of the total water bought/respondents. The reduction in NRW to acceptable levels is vital for the financial sustainability of the water utility. Measurements were taken at district water meters in the four zones of Chitungwiza. The benchmark value for NRW was targeted at $25 \%$, the levels achieved by the best performing utilities in developed countries.

Continuity of water supply: It was measured as the average number of hours of pressurised water supply per day. Performance benchmarking target value of $24 \mathrm{~h} 7 \mathrm{days}$ a week (24/7) supply was used.

Quality of water supplied: The potable water quality requirement is defined by the Standards Association of Zimbabwe (SAZ) and World Health Organization standards and guidelines for drinking water standards for least developed countries. The quality of the municipal water was not assessed at the lab. It was based on how households perceive the quality of the water they are receiving. Water quality assessment was benchmarked at $100 \%$. The assessment was based on the responses provided by households and the author's assessment of the water colour and taste in suburbs where water was available. Therefore, this indicator was expressed in qualitative terms (high and poor water quality). The quality of water supplied is an equally important performance indicator. Poor water quality can pose serious public health hazards. Waterborne diseases (cholera and typhoid) are quite common in Chitungwiza (Fernández et al. 2011; Fisher 2009). Therefore, this performance indicator must be regularly monitored, and the benchmark should be excellent and of high quality.

Efficiency in redressal for customer complaint: This was a ratio of the total number of water supply-related complaint redressed within $24 \mathrm{~h}$ of receipt of a complaint in 1 year (May 2016 - July 2017) to the total number of water supply related complaints received in the same given time period expressed as percentage. As water supply is an essential service, the benchmark for redress was benchmarked at $24 \mathrm{~h}$ or the next working day. 
TABLE 4: Performance indicators measured in Chitungwiza in 2017.

\begin{tabular}{|c|c|c|}
\hline Indicator & Benchmark & Conditions in Chitungwiza \\
\hline Coverage of water supply connection & $100 \%$ & $89.7 \%$ \\
\hline $\begin{array}{l}\text { Extent of metering of water } \\
\text { connections }\end{array}$ & $100 \%$ & $80.2 \%$ \\
\hline Extent of non-revenue water & $25 \%$ & $55 \%$ \\
\hline Continuity of water supply & $24 / 7$ & $20 \mathrm{~min}-3$ days/week \\
\hline Quality of water supplied & High & Poor \\
\hline $\begin{array}{l}\text { Efficiency in redressal of customer } \\
\text { complaints }\end{array}$ & $24 \mathrm{~h}$ & At earliest $48 \mathrm{~h}$ \\
\hline
\end{tabular}

$n=289$.

were not as accurate as they should be because amongst the four zones in Chitungwiza, Seke north zone had other suburbs without district bulk water meters. Eleven district meters have been purchased ready for installation (from the interview with Water Director). This will facilitate the measurement of real losses. Most NRW water in Chitungwiza was from real and physical losses. These losses were through illegal and unmetered connections, inaccurate meter reading and distribution system leakages.

\section{Causes of high non-revenue water in Chitungwiza}

Leakages and ageing infrastructure: Leakages in the municipal water distribution system were observed as a major contributor to high NRW in Chitungwiza. To contextualise the problem, leakages in Chitungwiza are identified by households in their neighbourhoods, municipal workers (during operations whilst doing connections and repairs) and municipal police during patrols. Despite speedy reporting of leakages, Chitungwiza municipality does not attend to the leakage reports with urgency. Most households surveyed were not happy with the municipality leakage response time, which in most cases is said to take at the earliest 2 days but can extend to weeks. Table 5 shows the leakages recorded between May 2016 and July 2017 (1 year before survey). A total of $40.9 \%$ leakages were reported, but the municipality's reaction time was slow with a minimum of $48 \mathrm{~h}$, thus increasing the NRW in Chitungwiza as more treated water is lost from the system through leakages without being accounted.

Late and slow leakage response by the municipality reflects a poorly maintained water system that mirrors poor service provision. Water infrastructure in Chitungwiza was installed five decades ago. As a result of economic meltdown in Zimbabwe, the Chitungwiza system was severely affected. Renovation and expansion of new water infrastructure has been suspended. This has put pressure on the existing ageing infrastructure as the population and town activities are expanding rapidly.

Illegal and unmetered connections: Discussions with the Director of Water Department and the Chief Technician revealed that illegal connections are decreasing, and this agreed with the service- level benchmarking (SLB 2016) report of the preceding year. This is because of the implementation of tough measures and penalties introduced by the municipality for illegally connecting for water. A \$200 plus administration fee was charged for illegal
TABLE 5: Leakage statistics from surveyed households.

\begin{tabular}{lcccc}
\hline Zone & $\begin{array}{c}\text { Leakages } \\
\text { recorded }\end{array}$ & No leakages & $\begin{array}{c}\text { No information } \\
\text { provided }\end{array}$ & Total \\
\hline Seke South & 22 & 50 & 5 & 77 \\
Seke North & 21 & 24 & 4 & 49 \\
Zengeza & 56 & 42 & 5 & 103 \\
St Mary's & 23 & 46 & 0 & 69 \\
\hline Total & $\mathbf{1 2 2}$ & $\mathbf{1 6 2}$ & $\mathbf{1 4}$ & $\mathbf{2 9 8}$ \\
Proportion (\%) & $\mathbf{4 0 . 9}$ & $\mathbf{5 4 . 4}$ & $\mathbf{4 . 7}$ & $\mathbf{1 0 0}$ \\
\hline$n=298$. & & & &
\end{tabular}

connectors. This means, it is expensive if households are caught because the formal connection costs $\$ 44$ plus the cost of buying your individual water meter. Chitungwiza municipality does not charge for connecting. Illegal connections are identified by the municipal workers and police. This team is also responsible for monitoring the distribution system and leakage identification. However, other respondents argue that the fines charged to illegal connectors were not punitive, because they believed that in the long run their yearly water payments surpass the fine paid by illegal connectors. During household survey and system surveillance, illegal connections were identified (see Figure 2). Cases of water theft were identified in Chitungwiza. This has contributed to the high NRW in Chitungwiza. Concerted effort is required from both parties, the utility provider to maintain and repair the ageing infrastructure and households to stop and report illegal connections and water theft cases. Municipal police are said to be involved in illegal connections as they were bribed by illegal users during their operations.

\section{Coverage of water supply}

The study assessed the coverage of water supply in the four zones of the residential suburbs during survey and system surveillance. Municipal water coverage in Chitungwiza residential suburbs was not $100 \%$. Unserved suburbs with no municipal water supply system were identified. Three extension suburbs had no municipal connections: Unit A, L and P. One extreme case was of a suburb in Seke south zone without municipal water supply or boreholes. They completely rely on household wells and some use installed submersible pumps in the wells, feeding into bulk tanks that are connected to the houses. Across the four zones in Chitungwiza, supply of municipal water with low pressure was consistent.

\section{Municipal boreholes}

Municipal boreholes are a very important water source in Chitungwiza. The total number of municipal boreholes, their condition and distribution were observed because recently the population relying on boreholes has been increasing. Non-governmental organisations have been playing an important role in the drilling of municipal boreholes in Chitungwiza to improve access to water and security.

Reliance on borehole water has increased because of the chronic intermittent and unreliable municipal water supply 

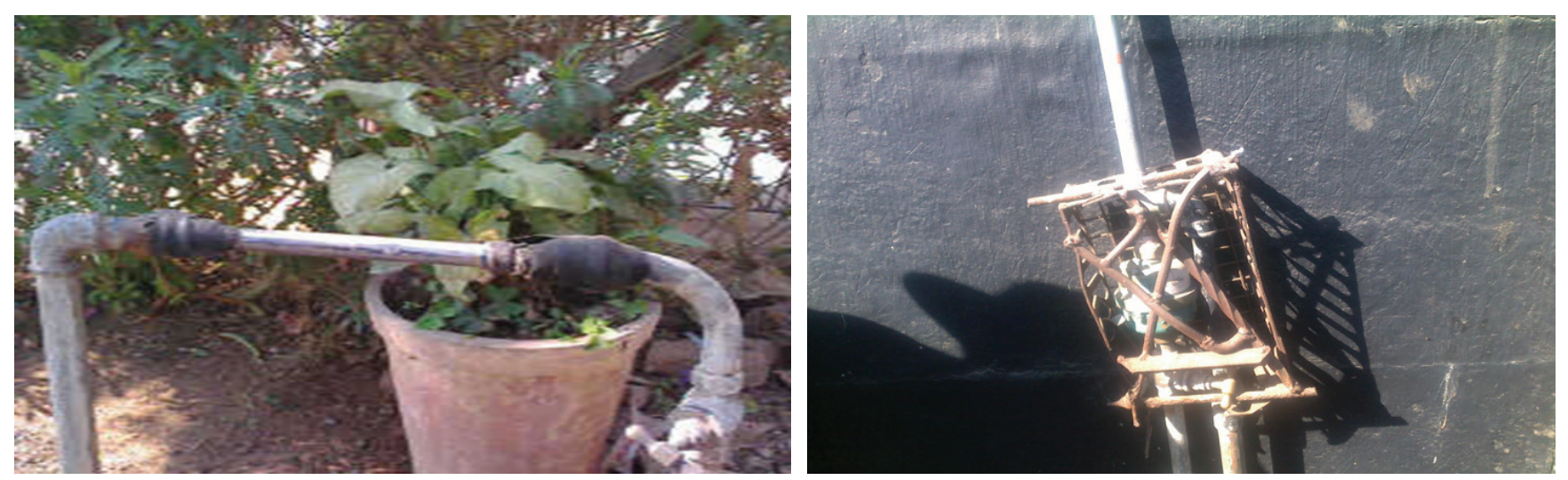

FIGURE 2: Evidence of illegal connection and meter by-passing in Chitungwiza.

TABLE 6: Non-governmental organisation donated boreholes in suburbs of Chitungwiza.

\begin{tabular}{lc}
\hline Organisation/NGO & Number of boreholes donated \\
\hline UNICEF & 18 \\
ADRA & 12 \\
German AGRO Action (GAA) & 5 \\
Healthcare centre & 3 \\
Mescops & 1 \\
Municipality (AfDB fund) & 10 \\
\hline
\end{tabular}

Source: Chitungwiza Water Department (2017 report)

ADRA, Adventist Development and Relief Agency; AfDB, African Development Bank; GAA, German AGRO Action; NGO, Non-Governmental Organisations; UNICEF, United Nations International Children's Emergency Fund.

and the quality issues associated with the current water supplied. Sixty-five boreholes were working whilst 14 were non-functional. Non-functional boreholes had worn out rods and some had dried out because of poor siting. In some cases, households were making contributions to repair malfunctioning municipal boreholes. Challenges facing Chitungwiza municipality to repair boreholes are related to lack of spares to replace worn out parts and inadequate funds to procure the parts.

\section{Water supply and management issues in Chitungwiza}

During the household survey, several important water supply and management challenges that indicate water system performance were mentioned. Most of the respondents $(80 \%)$ expressed dissatisfaction with the current water supply system and the water-related services. Households unveiled several problems and the most recurring problems. The order of ranked problems is listed in Table 7.

\section{Water supply services rating}

Household service rating of Chitungwiza municipality water services: Household perception and water service provision rating were assessed. These perceptions are important as they define the relationship between the utility provider (municipality) and its clients/households. Household perception and their rating of the services determine their willingness to pay for water services. The following have been identified as key issues.
TABLE 7: Order of ranked Chitungwiza water supply and management problems.

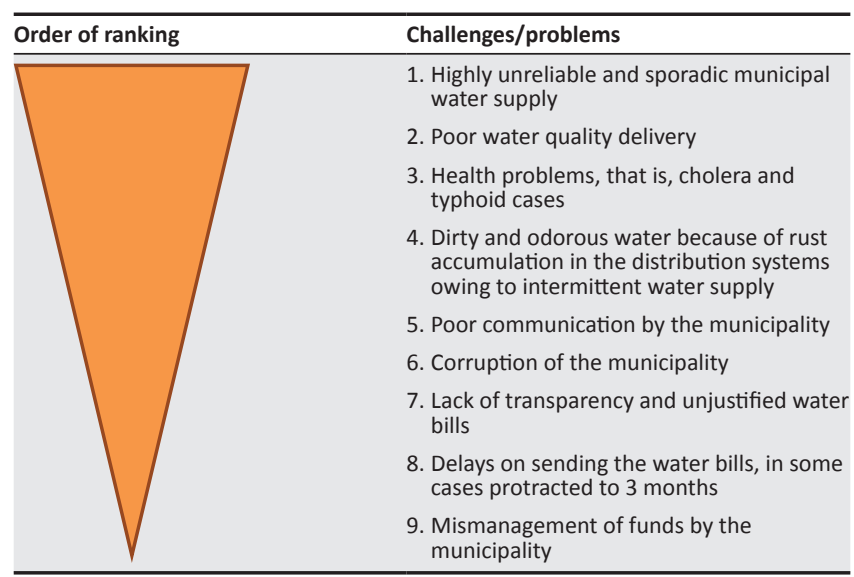

Note: The width of the arrow represents the most ranked problem and tip of the arrow represents the least ranked problem.

Household perceptions on the quality of municipal water: A majority of the respondents, $90.3 \%$, ranked the municipal water quality as poor. The results are consistent with a study conducted in twosuburbs of Chitungwiza (Unit K and J) by Gambe (2019), where $80.3 \%$ of the interviewed residents describe the quality of municipal water supply as poor. Many respondents describe the water as odorous, with suspended solids and of bad colour. These quality traits were also consistent with Gambe (2019) study in which residents describe the water as brownish in colour with an unpleasant smell, especially on the day supplies are reconnected. Water colour was affected by dry pipes that allowed rust to accumulate before the next supply. Households in Chitungwiza have adopted a variety of alternative and private investment choices to combat low quality and which disrupted paying for municipal potable water.

Level of service satisfactory: A majority of the respondents, $80.2 \%$, rated the municipal water supply services as poor, defined by unreliable water supply services, poor water quality supply, unjustified bills that are not delivered on time and poor communication between utility provider and residents. Only $3.4 \%$ of the respondents were happy with the level of water service provision. There is communication gap between utility provider and residents. This indicates a lack of transparency. 
Figure 3 highlights that household ratings for both the quality of municipal water supply and the household satisfaction were extremely poor. This reflects a deep management failure by the Chitungwiza municipality. Every water utility provider thrives by improving service provision to facilitate water-user payments, which Chitungwiza municipality failed dismally. This is affecting water revenue generation and subsequently leads to the broader failure of the whole system as the utility provider lacks reliable revenue generation to improve water services. Figure 3 shows expanded household perception on the quality of municipal quality supply and satisfactory service rating of the water supply services of Chitungwiza municipality.

Since majority of the households widely perceived the quality of municipal water as very poor, households have embarked on various coping strategies. These include boiling of municipal water before drinking, pretreatment using water guard on both municipal and well water before drinking, use of borehole water and purchasing drinking water from supermarkets. Gambe (2019) also found out that in two suburbs of Chitungwiza, $75 \%$ of respondents revealed that they no longer use the municipal water for consumption

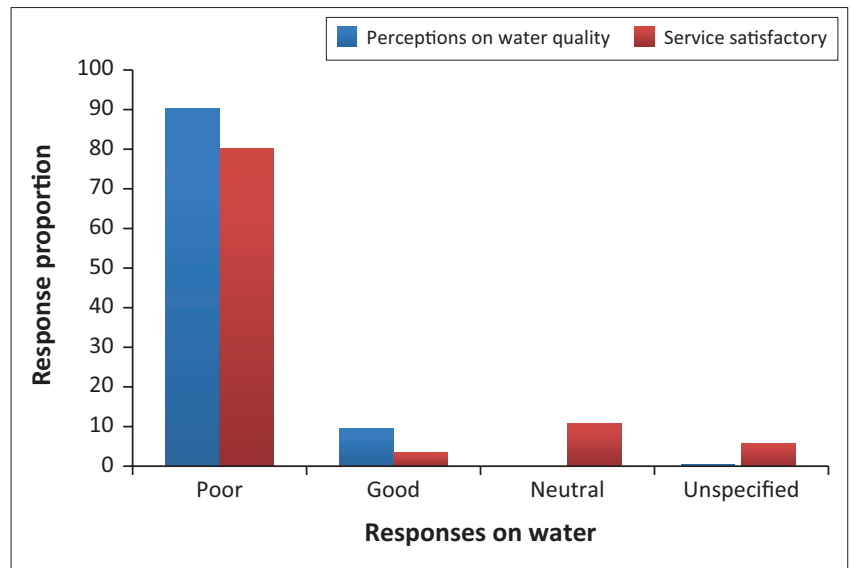

$n=298$.

FIGURE 3: Household perception on municipal water quality and level of water supply service satisfaction.

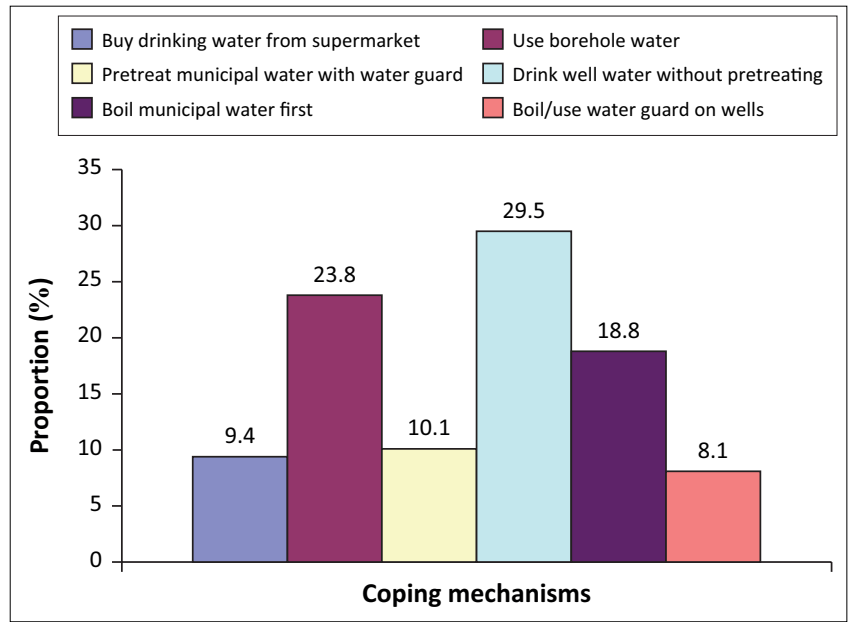

FIGURE 4: Common coping strategies amongst households in Chitungwiza. purposes. Figure 4 shows the coping mechanisms that residents in Chitungwiza are using to deal with the poor municipal water supply.

The choice of coping strategy was influenced by the distribution of municipal boreholes, income level and education. The use of well water was common in newly developed areas not yet serviced.

\section{Water supply in Chitungwiza}

Chitungwiza residents are facing unreliable and poor water supply services, with the majority of households perceiving the municipal water to be of poor quality. Although this study did not conduct the lab tests on the municipal water to assess its quality, measurements related to water quality were based on the responses provided by households. Water was observed to be available 1-2 days per week in most suburbs. The water supply distribution system is poorly maintained, the municipality is not replacing either broken and stolen meters as they are mandated to do so, leakages were prevalent and not attended on time. These results were consistent with previous research (Drangert \& Sharatchandra 2017; Hess et al. 2017; Vaux et al. 2020). The water supply system also lacks monitoring, which has encouraged illegal connections and water theft in Chitungwiza suburbs.

Most of the NRW in Chitungwiza is from real losses. Nonrevenue water can be reduced through appropriate technical and managerial actions and monitoring NRW can trigger such corrective measures (Yadav et al. 2014). The following measures can be implemented to reduce NRW in Chitungwiza:

- Improve bursts and leakage reporting (early reporting).

- Timely attendance to leakages, pipe bursts.

- Replace old pipes on time.

- Tough regulations on illegal connections, with high fines or jail sentence.

- Accurate meter reading and investment in the modern meters and metering.

Some cities in developing countries such as India have benefited from effective leakage reporting system through social media (Gupta et al. 2016). Chitungwiza can use the same approach, drawing lessons from these cities on the effectiveness of social media reporting and awareness for households through platforms such as Twitter, WhatsApp, Facebook and short message services (SMSs).

\section{Water supply and management problems in Chitungwiza}

In extensive discussions with households throughout the data collection, several water challenges that households are facing with the municipal water supply services were expanded.

Trust: Lack of household trust in municipal water services provision was consistent throughout data collection. 
Owing to chronic poor water service delivery, residents have completely lost trust in the municipal water supply in Chitungwiza. Ninety per cent of the residents lack trust and they do not rely on municipal water anymore as indicated by the switch to various alternative sources (Figure 3).

Corruption and mismanagement: Residents believe that corruption in Chitungwiza municipality has affected water services provision. These results are consistent with other researches elsewhere in countries such as Nigeria (Emenike et al. 2017), South Africa (Adams, Sambu \& Smiley 2018; Bischoff-Mattson et al. 2020) and Malawi (Adams 2018). Corruption was mainly through illegal reconnection of the households that have water access officially cut off by the municipality. Municipal teams responsible for disconnecting meters of non-compliant households were believed to be corrupt. They were disconnecting water during the day and came at night asking for bribes to reconnect. Households revealed they mostly ask \$5 to reconnect. Households also argued that municipal workers were living a luxurious life at the expense of poor water services delivery.

Unreliable municipal water supply services: Households showed dissatisfaction with intermittent and unreliable municipal water supply services. Ninety per cent of the households rated municipal water supply and related services as highly unreliable. A research by Adams (2018) in Lilongwe slums in Malawi produced similar results. To cope with unreliable municipal water supply, residents have implemented a 'source switch' where households resort to using various alternative sources, although some of the sources are not safe and reliable. Sixty-two per cent of the householders interviewed had private wells and boreholes that supplied water for both drinking and domestic use. Wells and private boreholes have become a coping mechanism vto adapt to unreliable municipal water supply services. In other regions residents use rainwater harvesting technology (Emenike et al. 2015; Nnaji \& Mama 2014) such as rooftops, gutters and bulk tanks but the technology was not common in Chitungwiza.

Households believe their new sources to be more reliable than municipal water. Another proportion of the interviewees purchased bottled water from supermarkets for drinking and felt safe with this source, but this is not sustainable in the long run. About $13.1 \%$ had submersible pumps in their households that were connected to bulk tanks of $5000 \mathrm{~L}-1000 \mathrm{~L}$. The private systems were connected to the municipal system supplying the whole house through meter by-passing. Figure 5 shows the detailed questionnaire survey on household water sources alternative to municipal water supply that are adopted in the four zones of Chitungwiza. Municipal boreholes are not included.

In totality, $51.7 \%$ of the 298 surveyed households in the four zones of Chitungwiza rely on homestead wells. However,

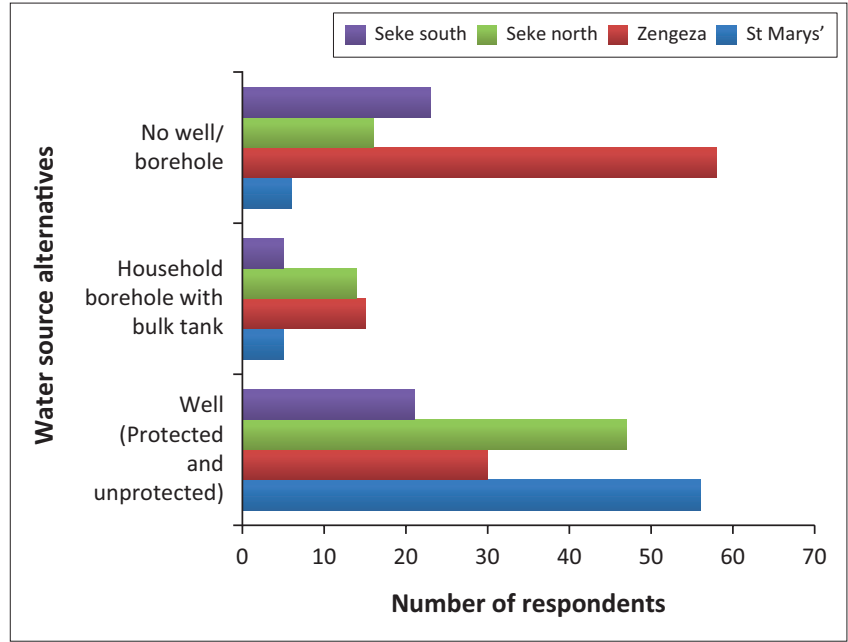

$n=298$.

FIGURE 5: Adopted household water source alternatives to poor municipal water supply in Chitungwiza.

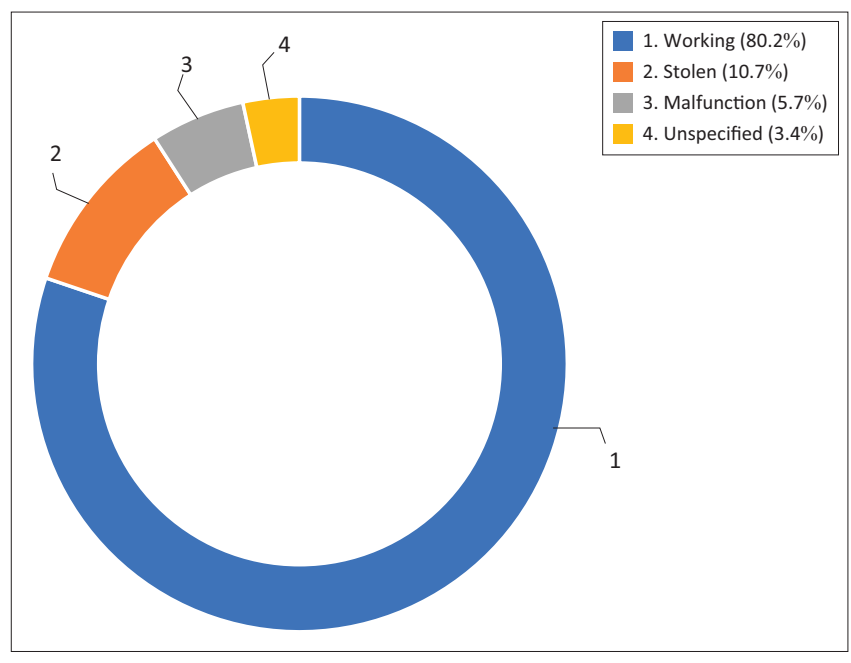

$n=298$.

FIGURE 6: Water meter conditions in Chitungwiza.

water quality for these wells remains unknown. To address the challenge, some households have been practicing point of use treatment methods of the water with water guarding, others boil the water whilst some do nothing (Figure 4). The results of the pretreatment of well water for drinking purposes are consistent with Emenike et al. (2017) where households in South-West Nigeria apply various point of use treatment measures to compensate for poor water quality delivered by municipality.

Lack of accountability and transparency: Households expressed concerns over the lack of transparency and accountability of the council on the management of finances and other resources. The municipality was not sending bills on time to the residents. Water users complained that they were paying their debts without seeing changes to water bill debts. That dampened the efforts by water users to pay because they believe the system lacks transparency (Koehler, Thomson \& Hope 2016). Households accused the municipality of not being accountable. 
Poor and unattended water infrastructure: Some households had malfunctioning water meters and some had been stolen. In Chitungwiza, water meters are the property of the municipality and it is the responsibility of the municipality to replace stolen or malfunctioning water meters. About $14.1 \%$ of households had either stolen or malfunctioning meters. Old malfunctioning and stolen water meters were not replaced. In some cases, municipal workers were accused of asking for bribes to repair malfunctioning meters. Figure 6 highlights the overall water meter conditions in Chitungwiza.

\section{Conclusion and recommendations}

Chitungwiza municipality water supply services are failing to meet the benchmark of all the performance indicators investigated that are key for water services delivery. Chitungwiza does not have its own water treatment plant, which means the burden of managing a water treatment is transferred to Harare water but despite this, they are failing to maximise on this to realise continuous water supply by increasing their purchasing power of water from Harare Water. The study established the following as major issues in the current water system: unreliable municipal water supply leading to the lack of residents' trust in the whole system, supply of poor water quality, poor maintenance, slow attendance to leakages that are leading to high NRW, lack of transparency and accountability by the municipality. Other factors are mismanagement of the water supply and corruption by the municipality. Majority of the households, $80.2 \%$, rated the municipal water supply services provision as poor. This reflects a serious problem between residents and the municipality that need urgent solutions through structural and institutional reforming of the municipality. The study recommends the following:

- Chitungwiza municipality should consider implementing structural reforms that would allow the current situation to be improved.

- The municipality should improve on transparency, accountability and management and end corruption.

- Improvement in the quality of municipal water supply is vital. Further studies are required to assess water quality of boreholes and wells that are used by households.

\section{Acknowledgements}

The author acknowledges the willingness of the participants of all the households interviewed. The author is also grateful of the full support received from the Chitungwiza municipality.

\section{Competing interests}

The author declares no known competing financial interests or personal relationship that could have appeared to influence the work reported in this article.

\section{Authors' contributions}

All work associated with the writing of this article was done by the author L.Z.

\section{Funding information}

This research received no specific grant from any funding agency in the public, commercial or not-for-profit sectors.

\section{Data availability statement}

Data sharing is not applicable to this article as no new data were created or analysed in this study.

\section{Disclaimer}

The views and opinions expressed in this article are those of the author and do not necessarily reflect the official policy or position of any affiliated agency of the author.

\section{References}

Aboelnga, H.T., El-Naser, H., Ribbe, L. \& Frechen, F.-B., 2020, 'Assessing water security in water-scarce cities: Applying the Integrated Urban Water Security Index (IUWSI) in Madaba, Jordan', Water 12(5), 1299. https://doi.org/10.3390/ w12051299

Adams, E.A., 2018, 'Thirsty slums in African cities: Household water insecurity in urban informal settlements of Lilongwe, Malawi', International Journal of Water Resources Development 34(6), 869-887. https://doi.org/10.1080/07900627.201 7.1322941

Adams, E.A., Sambu, D. \& Smiley, S.L., 2018, 'Urban water supply in sub-Saharan Africa: Historical and emerging policies and institutional arrangements', International Journal of Water Resources Development 35(2), 240-263. https://doi.org/10.10 80/07900627.2017.1423282

Adams, E.A. \& Zulu, L.C., 2015, 'Participants or customers in water governance? Community-public partnerships for peri-urban water supply', Geoforum 65(1), 112-124. https://doi.org/10.1016/j.geoforum.2015.07.017

Africa Water Facility, 2009, Chitungwiza water and sanitation rehabilitation project Appraisal Report, Africa Development Bank, Harare, viewed 04 March 2020 from https://www.africanwaterfacility.org/fileadmin/uploads/awf/Projects/AWFProject-appraisal-report-ZIMBABWE.pdf.

Ahmadi, M.S., Sušnik, J., Veerbeek, W. \& Zevenbergen, C., 2020, 'Towards a global day zero? Assessment of current and future water supply and demand in 12 rapidly developing megacities', Sustainable Cities and Society 61(1), 102295. https://doi. org/10.1016/j.scs.2020.102295

Ainuson, K.G., 2010, 'Urban water politics and water security in disadvantaged urban communities in Ghana', African Studies Quarterly 11(4), 59-82.

Bischoff-Mattson, Z., Maree, G., Vogel, C., Lynch, A., Olivier, D. \& Terblanche, D., 2020, 'Shape of a water crisis: Practitioner perspectives on urban water scarcity and "Day Zero" in South Africa', Water Policy 22(2), 193-210. https://doi.org/10.2166/ wp.2020.233

Booysen, M.J., Visser, M. \& Burger, R., 2019, 'Temporal case study of household behavioural response to Cape Town's "Day Zero" using smart meter data', Water Research 149(1), 414-420. https://doi.org/10.1016/j. watres.2018.11.035

Britto, A.L., Maiello, A. \& QuintsIr, S., 2019, 'Water supply system in the Rio de Janeiro Metropolitan Region: Open issues, contradictions, and challenges for water access in an emerging megacity', Journal of Hydrology 573(1), 1007-1020. https:// doi.org/10.1016/j.jhydrol.2018.02.045

Chen, Y., Zhou, H., Zhang, H., Du, G. \& Zhou, J., 2015, 'Urban flood risk warning under rapid urbanization', Environmental Research 139(1), 3-10. https://doi. org/10.1016/j.envres.2015.02.028

Clifford Holmes, J.K., Slinger, J.H., Musango, J.K., Brent, A.C., \& Palmer, C.G., 2014 'Using system dynamics to explore the water supply and demand dilemmas of a small South African municipality', In 32nd International Conference of the System Dynamics Society, Delft, The Netherlands, 20-24 July 2014, Authors version, System Dynamics Society.

Drangert, J.O. \& Sharatchandra, H.C., 2017, 'Addressing urban water scarcity: Reduce, treat and reuse-the third generation of management to avoid local resources boundaries', Water Policy 19(5), 978-996. https://doi.org/10.2166/ wp. 2017.152

Emenike, C.P., Tenebe, I.T., Omole, D.O., Ngene, B.U., Oniemayin, B.I., Maxwell, O. et al, 2017, 'Accessing safe drinking water in sub-Saharan Africa: Issues and challenges in South-West Nigeria', Sustainable Cities and Society 30(1), 263-272. https://doi.org/10.1016/j.scs.2017.01.005 
Fernández, M.Á., Mason, P.R., Gray, H., Bauernfeind, A., Fesselet, J.F. \& Maes, P., 2011, 'Descriptive spatial analysis of the cholera epidemic 2008-2009 in Harare, Zimbabwe: A secondary data analysis', Transactions of the Royal Society of Tropical Medicine and Hygiene 105(1), 38-45. https://doi.org/10.1016/j. trstmh.2010.10.001

Fisher, D., 2009, 'Cholera in Zimbabwe', Annals of the Academy of Medicine, Singapore $38(1), 193$

Gambe, T.R., 2019, 'The gender dimensions of water poverty: Exploring water shortages in Chitungwiza', Journal of Poverty 23(2), 105-122. https://doi.org/10. 1080/10875549.2018.1517399

Gupta, A., Mishra, S., Bokde, N. \& Kulat, K., 2016, 'Need of smart water systems in India', International Journal of Applied Engineering Research 11(4), 2216-2223.

Hess, D.J., Wold, C.A., Worland, S.C. \& Hornberger, G.M., 2017, 'Measuring urban water conservation policies: Toward a comprehensive index', Journal of the American Water Resources Association 53(2), 442-455. https://doi.org/10.1111/1752 1688.12506

Hove, M. \& Tirimboi, A., 2011, 'Assessment of Harare water service delivery', Journa of Sustainable Development in Africa 13(1), 61-84.

Japan International Cooperation Agency (JICA), 2013, The project for the improvement of water supply, sewage and solid waste management in Chitungwiza in the Republic of Zimbabwe, Final Report, viewed 02 March 2020, from http://open jicareport.jica.go.jp/pdf/12125704_01.pdf.

Koehler, J., Thomson, P. \& Hope, R., 2016, 'Mobilizing payments for water service sustainability', in E. Thomas, (ed.), Broken pumps and promises, pp. 57-76, Springer, Cham.

Larsen, T.A., Hoffmann, S., Lüthi, C., Truffer, B. \& Maurer, M., 2016, 'Emerging solution to the water challenges of an urbanizing world', Science 352(6288), 928-933. https://doi.org/10.1126/science.aad8641

Nnaji, C.C. \& Mama, N.C., 2014, 'Preliminary assessment of rainwater harvesting potential in Nigeria: Focus on flood mitigation and domestic water supply', Water Resource Management 28(1), 1907-1920. https://doi.org/10.1007/s11269-0140579-1
Nyikadzino, T. \& Nhema, A.G., 2015, 'The implications of centre-local relations on service delivery in local authorities in Zimbabwe: The case of Chitungwiza', Journa of Public Administration and Governance 5(2), 149-168. https://doi.org/10.5296/ of Public Adming.v5i2.7751

Padowski, J.C., Carrera, L. \& Jawitz, J.W., 2016, 'Overcoming urban water insecurity with infrastructure and institutions', Water Resources Management 30(13), 4913-4926. https://doi.org/10.1007/s11269-016-1461-0

Roberts, D., 2008, 'Thinking globally, acting locally - Institutionalizing climate change at the local government level in Durban, South Africa', Environment and Urbanization 20(2), 521-537. https://doi.org/10.1177/0956247808096126

Rouse, M., 2014, 'The worldwide urban water and wastewater infrastructure challenge', International Journal of Water Resources Development 30(1), 20-27. https://doi.org/10.1080/07900627.2014.882203

Service Level Benchmarking (SLB), 2016, Chitungwiza municipality SLB report, Final Report, Service Level Benchmarking, Chitungwiza.

Vaux, Jr. H., Vammen, K., Bernex, N., Fabrega, J., Forde, M., Roldan, G. et al., 2020, 'The challenges of managing the urban waters of the Americas', Environment: Science and Policy for Sustainable Development 62(2), 14-29. https://doi.org/10.1080/0 0139157.2020.1708170

World Bank, 2014, The limits and possibilities of prepaid water in Urban Africa: Lessons from the field, viewed 03 March 2020, from http://documents.worldbank.org/ curated/en/499021468010486033/pdf/901590REPLACEMOPrepaidOWaterOAfr ca.pdf.

World Bank Report, 2014, Greater Harare water and sanitation strategic plan viewed 03 March 2020, from http://documents1.worldbank.org/curated/ viewed 03 March 2020, from http://documents1.Worldbank.org/curated/ GHWSIP-Report-Final-Volume-I-WB.pdf.

Yadav, S.M., Singh, N.P., Shah, K.A. \& Gamit, J.H., 2014, 'Performance evaluation of water supply services in developing country: A case study of Ahmedabad city',
KSCE Journal of Civil Engineering 18(7), 1984-1990. https://doi.org/10.1007/ S12205-014-0306-8

Zimmerman, J.B., Mihelcic, J.R. \& Smith, J., 2008, 'Global stressors on water quality and quantity', Environmental Science and Technology 42(12), 4247-4254. https:// doi.org/10.1021/es0871457 